\title{
Form, function and evolutionary significance of stridulatory organs in ant nest beetles (Coleoptera: Carabidae: Paussini)
}

\author{
ANDREA DI GIULIO ${ }^{1}$, Simone FATTORINI ${ }^{2}$, Wendy MOORE ${ }^{3}$ JAMES ROBERTSON $^{3}$ and EMANUEla MAURIZI ${ }^{1}$ \\ 1'Department of Science, University “Roma Tre”, Viale G. Marconi 446, 00146, Roma, Italy; e-mails: andrea.digiulio@uniroma3.it; \\ ${ }^{2}$ Azorean Biodiversity Group (ABG, CITA-A) and Portuguese Platform for Enhancing Ecological Research \& Sustainability \\ (PEERS), University of the Azores, Rua Capitão João d'Ávila, 9700-042 Angra do Heroísmo, Portugal; \\ e-mail: simone_fattorini@virgilio.it \\ ${ }^{3}$ Department of Entomology, University of Arizona, Tucson, AZ, USA; e-mails: wmoore@email.arizona.edu; erotylid@gmail.com
}

Key words. Carabidae, Paussinae, Paussini, ant nest beetles, acoustical mimicry, stridulatory organs, SEM, FIB/SEM, Paussus, Euplatyrhopalus, Platyrhopalopsis

\begin{abstract}
Stridulatory organs in the myrmecophilous carabid beetle tribe Paussini have long been recognized and used as a defining character of some genera and higher level taxa, however their morphology has only roughly been described. Here, we describe the fine morphology of Paussini stridulatory organs using scanning electron (SEM) and focused ion beam (FIB) microscopy. Within this tribe, there are three types of stridulatory organs, each with different positions of the scraper (plectrum) and file (pars stridens). Type I (abdomen-femur type) is located on the abdomen (scraper) and metafemur (file) in the subtribe Paussina (sensu Geiselhardt et al., 2007, Naturwissenschaften 94: 871-894). Type II (thorax-femur type) and Type III (femur-thorax type) are located on the mesothorax and mesofemur in two different genera of the subtribe Platyrhopalina, however in Euplatyrhopalus the scraper is located on the mesothorax and the file is located on the mesofemur (Type II), whereas in the genus Platyrhopalopsis the structures are reversed in that the file is located on the mesothorax and the scaper is located on the mesofemur (Type III). The independent evolution of three types of stridulatory organs in three lineages of Paussini suggests that acoustical communication has played an important role in the evolution of ant nest beetles. While the roles of stridulation in this group remain speculative, we verified that all three types of stridulatory organs are present in both sexes and are similar to stridulatory organs known in their host ants which also use stridulation as a method of communication. We discuss the possibility that the beetles' stridulation could (1) facilitate their exploitation of ant colonies, and (2) be involved in mate recognition and courtship.
\end{abstract}

\section{INTRODUCTION}

Stridulatory organs are known in adults and larvae from 30 beetle families (see Wessel, 2006 for an updated review), with at least 20 different, independently evolved types in both Adephaga (especially Hygrobiidae, Dytiscidae and Carabidae) and Polyphaga (especially Staphyliniformia, Scarabaeiformia, Bostrichiformia and Cucujiformia). Stridulation in beetles is produced by an amazing diversity of cuticular structures, involving a wide range of body parts and hypothesized functions (Schiödte, 1874; Gahan, 1900; Arrow, 1904, 1942; Wessel, 2006). Compared to other orders of insects, like Orthoptera and Auchenorrhyncha, very little is known about the physiological mechanisms influencing sound production and reception in Coleoptera (Lehr, 1914; Schneider, 1950; Tembrock, 1960; Spangler, 1988; Yager \& Spangler, 1995; Forrest et al., 1997; Yager, 1999). Stridulation in beetles most likely has different functions in different species and can involve both intraand inter-specific signalling. In the past it was assumed that stridulation has a functional role during courtship, acting as an prezygotic reproductive isolating mechanism (Wessel, 2006). More recent work indicates that stridulation plays additional roles, especially in startling behaviors, signaling distress and deterring predators (e.g. advertising unprofitability) (Dumortier, 1963; Claridge, 1974; Bauer, 1976; Masters, 1979, 1980; Lewis \& Cane, 1990; Schmitt \& Traue, 1990; Riede \& Stueben, 2000), but also in aggregating conspecifics in subsocial species (Niemits, 1972; Schuster, 1983). A few cases of acoustical mimicry have been reported whereby profitable species produce stridulations similar to the sounds of unprofitable species (e.g. Silphidae mimicking Bombus bees, see Lane \& Rothschild, 1965).

Despite the extraordinary number of myrmecophilous beetle species, belonging to at least 35 families (Hölldobbler \& Wilson, 1990; Mynhardt, 2013), stridulatory organs are known only within the ant nest beetles (Carabidae, Paussinae, Paussini); however, Luna de Carvalho (1953) briefly mentioned seeing a structure resembling a stridulatory organ in two myrmecophilous Thorictidae species. Paussini are obligate ant symbionts and predators, exhibiting refined morphological and behavioral adaptations for living with ants (Geiselhardt et al., 2006; Di Giulio et al., 2009, 2012; Maurizi et al., 2012).

Adults of four ant subfamilies (Ponerinae, Pseudomyrmecinae, Myrmicinae, Ectatomminae) are able to produce low frequency sound by stridulation (Mark1, 1965; Ferreira et al., 2010), which they use in intraspecific communication and aggregation, often integrating, amplifying and/ 
or modulating chemical cues (Markl \& Hölldobler, 1978; Baroni-Urbani et al., 1988; Hickling \& Brown, 2000; Hölldobler, 1999). Interestingly, immature stages of myrmecophilous riodinid and lycaenid butterflies also stridulate, producing sounds to comunicate with their host ants (De Vries, 1990, 1991a, b; Barbero et al., 2009a, b).

All members of the ground beetle tribe Paussini are highly specialized myrmecophiles, integrated in the ant societies (mainly guests of Myrmicinae and Formicinae: Geiselhardt et al., 2007). Paussines are generally considered ant parasites since they prey on adult ants and their brood without conferring any obvious benefit to the ant colonies (Escherich, 1899; Le Masne, 1961a, b; Geiselhardt et al., 2007; Di Giulio et al., 2011; Maurizi et al., 2012). It is still unclear which type of strategy these beetles use to enter and exploit the ants' nests without being attacked. Given the prevalence of trichomes and specialized setae adorning their body, it is assumed that the beetles are able to produce rewarding/appeasing chemicals from associated specialized glands, concentrated in the antennae, pronotum, elytra and pygidium (Nagel, 1979; Geiselhardt et al., 2007; Di Giulio et al., 2009, 2012; Maurizi et al., 2012). However, chemical and acoustical mimicry (Geiselhardt et al., 2007) could also be a part of their complex and effective parasitic strategy.

The presence of three types of stridulatory organs in Paussini has long been known, however the shape of these organs has only been superficially described (Westwood, 1874; Escherich, 1898; Gahan, 1922; Luna de Carvalho, 1949, 1953; Darlington, 1950; Nagel, 1987). Nagel (1987) and Geiselhardt et al. (2007) listed a potential new type of stridulatory organ in Paussini, involving an alary-elytral structure, however its role as a stridulatory organ remains speculative.

Lack of morphological and behavioural information on the stridulatory organs in Paussini inspired us to describe and illustrate the fine morphology of the three main types of stridulatory organs in ant nest beetles using scanning electron (SEM) and focused ion beam (FIB) microscopy. We compare and contrast these independently-evolved structures and present hypotheses for their potential functional role(s) and impacts on ant nest beetle diversification.

\section{MATERIAL AND METHODS}

\section{Terminology}

Throughout this paper we refer to the "file" as the finely ridged structure that forms one part of the stridulatory organ and the "scraper" as the peg-like stucture that forms the other part. In the literature different authors have adopted different definitions for these structures. Many follow Nichols \& Schuh (1989) who defined the "scraper" as the part or the organ that is actively rubbed over the "file". However, among insects, and even within paussines, the active half of the organ has widely different shapes. Therefore we refer to the "file" as the finely ridged half of the organ whether or not it is stationary or active.

Following the classification of Luna de Carvalho (1953), we describe three basic types of stridulatory organs in the tribe Paussini, hereafter called Type I, Type II and Type III, based on the position of the scraper (also known as plectrum) and the file (also known as pars stridens).
We selected the following three species as representatives of each stridulatory organ type for in-depth examination and detailed description: Type I (Fig. 1a) - Paussus favieri Fairmaire, 1851 ( 1 female and 1 male: "Morocco, High Atlas, Tizi-n-Test, 2063 m a.s.1., 5.v.2009”); Type II - Euplatyrhopalus vexillifer (Westwood, 1874) (1 female and 1 male: "British Bootang, Maria Basti, 1889") (note that the closely related species Euplatyrhopalus aplustrifer is shown in Fig. 1b); and Type III (Fig. 1c) - Platyrhopalopsis picteti (Westwood, 1874) (1 female: "Laos, Ban Kheun, 70 km N.W. Vientiane, 20.10.1968”, Muséum National d'Histoire Naturelle, Paris; 1 male: "Laos, Ban Na Hin, 15-21.5.2007").

In addition, specimens of Pheidole pallidula (Nylander, 1849) (Fig. 4), the host ant of Paussus favieri (5 workers, 5 soldiers and 1 queen: "Morocco, High Atlas, Tizi-n-Test, 2063 m a.s.l., 5.v.2009") were examined via SEM (Fig. 4b-f).

Beetles and ants were dissected under a stereomicroscope, kept overnight in a detergent-water solution, cleaned with ultrasound for $15 \mathrm{~s}$, rinsed in water, dehydrated through a series of ethanol baths of increasing concentration (70, 80, 90, 95 and 100\%), critical point dried (Bal-Tec CPD 030), mounted on a stub (by using self adhesive carbon disks), and observed via FIB/SEM (Dualbeam Helios - FEI, L.I.M.E. lab, University "Roma Tre", Rome, Italy) operating with the SEM column. The FIB/SEM is equipped with two columns including one electron beam (SEM column) and one ion beam (FIB column), oriented at $52^{\circ}$, and focused on the same point on the sample. Specimens of Paussus favieri were sputter-coated with gold (Emitech ${ }^{\circledR}$ K550 sputter coater) before observation (FIB/SEM set at $\mathrm{HV}=5 \mathrm{kV})$; specimens of Euplatyrhopalus vexillifer and Platyrhopalopsis picteti were observed uncoated at low voltage (FIB/SEM set at $\mathrm{HV}=1 \mathrm{kV})$.

The spines of the scraper of $P$. favieri prepared for the SEM were also analyzed with the FEI Dualbeam (FIB/SEM) Helios Nanolab operated with the ion column (FIB settings: $30 \mathrm{KV}$ and $0.92 \mathrm{nA}$ ) to investigate the internal cuticular structure of the spines (Fig. 3). The FIB was used to selectively ablate (milling process) a previously marked region of the sample using a focused ion current from a gallium source. The milling process was paused every few nanometers while high-resolution images were taken of the cross sections with the SEM column.

\section{RESULTS}

\section{Type I ("abdomen-femur" type)}

The highly derived abdomen-femur mechanism of Type I is present in all genera of the derived subtribe Paussina (including the speciose genus Paussus), except for the monospecific Leleupaussus. It involves structures positioned symmetrically on hind legs (file) and basal abdominal ventrites (scraper). This organ, present in both sexes (Escherich, 1898), is composed of a file comprising a slightly raised, finely ridged area positioned on the basal, inner (dorsal) face of the hind femora (Figs 1a3; 2a-b), that rubs against a fixed scraper, composed of a curved row of small spines (Fig. 1a2; 2c-d) [stridulatory file sensu Darlington, 1950, considered as pars stridens (stridulatory file) by Geiselhardt et al., 2007], positioned at both sides of abdominal ventrite 2 (Fig. 2c; ventrites 1-3 are connate and not clearly demarked). To produce the vibratory sound, the hind legs move up and down, either singly or in tandem (Maurizi et al., 2012).

Stridulatory file (Fig. 2a-b). The Type I file is suboval (maximum length $200 \mu \mathrm{m}$; maximum width $127 \mu \mathrm{m}$ ) and 

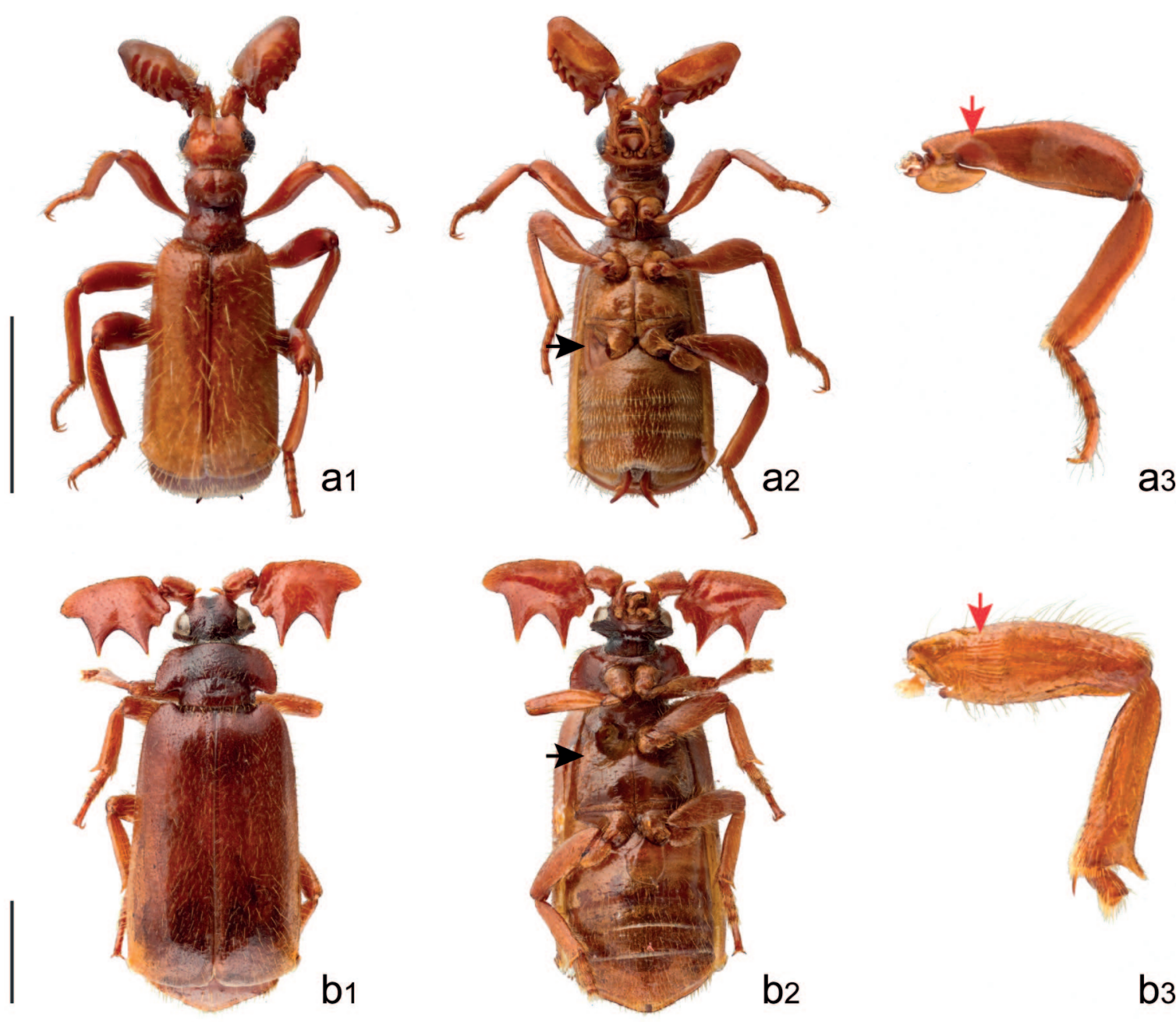

b3
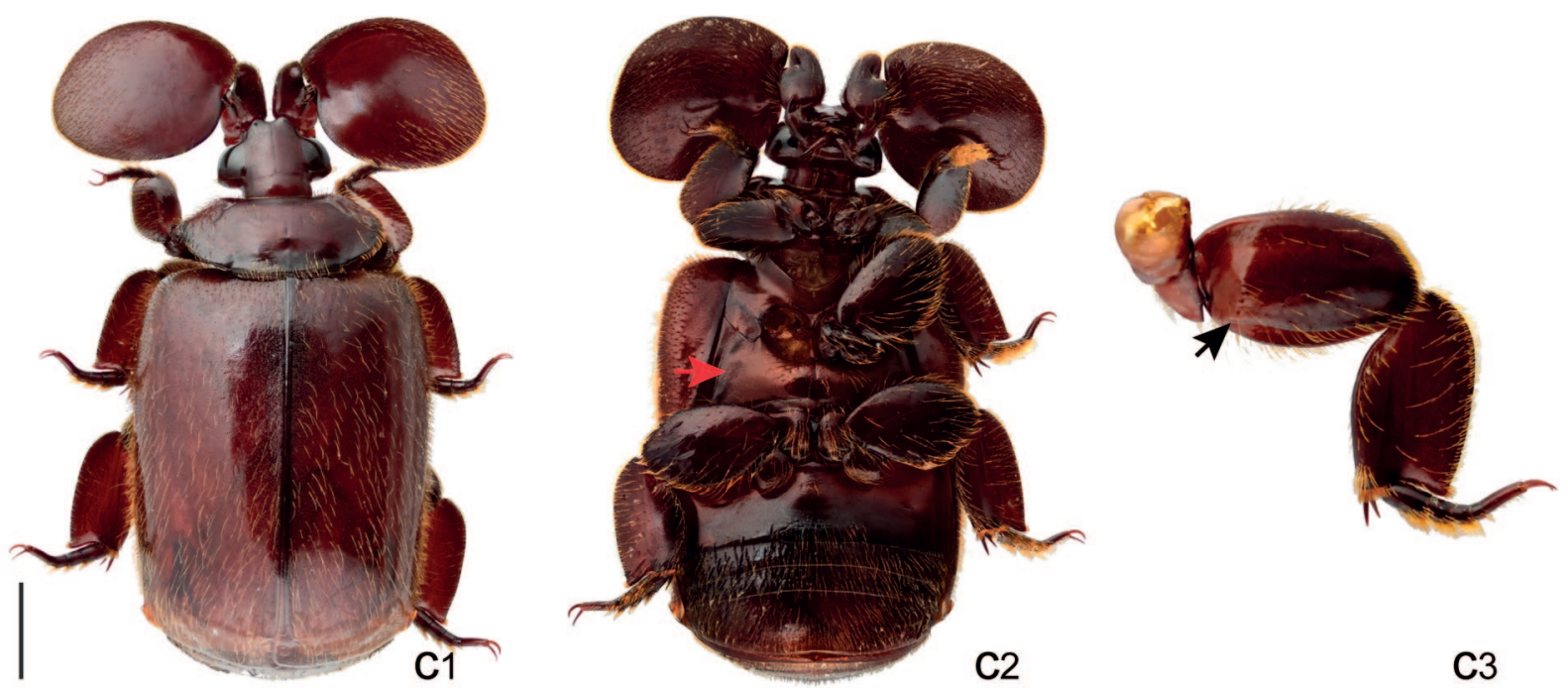

Fig. 1. Habitus dorsal, ventral with one "stridulatory" leg removed, and close-up of the removed leg in posterior view, showing the position of stridulatory file (red arrow) and scraper (black arrow). a1, a2, a3 - Paussus favieri, female, Type I (unique specimen identification number WM.0519); b1, b2, b3 - Euplatyrhopalus aplustrifer, sex undetermined, Type II (unique specimen identification number WM.0795); c1, c2, c3 - Platyrhopalopsis picteti, sex undetermined, Type III (unique specimen identification number WM.0511). Scale bars corresponding to dorsal habitus are $2 \mathrm{~mm}$. Note that the description for Type II is based on Euplatyrhopalus vexillifer.

oriented longitudinally along the leg axis, composed of $38-45$ subparallel ridges; ridges $1.57 \pm 0.14 \mu \mathrm{m}$ thick and approximately $1.62 \pm 0.43 \mu \mathrm{m}$ apart; most ridges complete and parallel, others incomplete and convergent. 

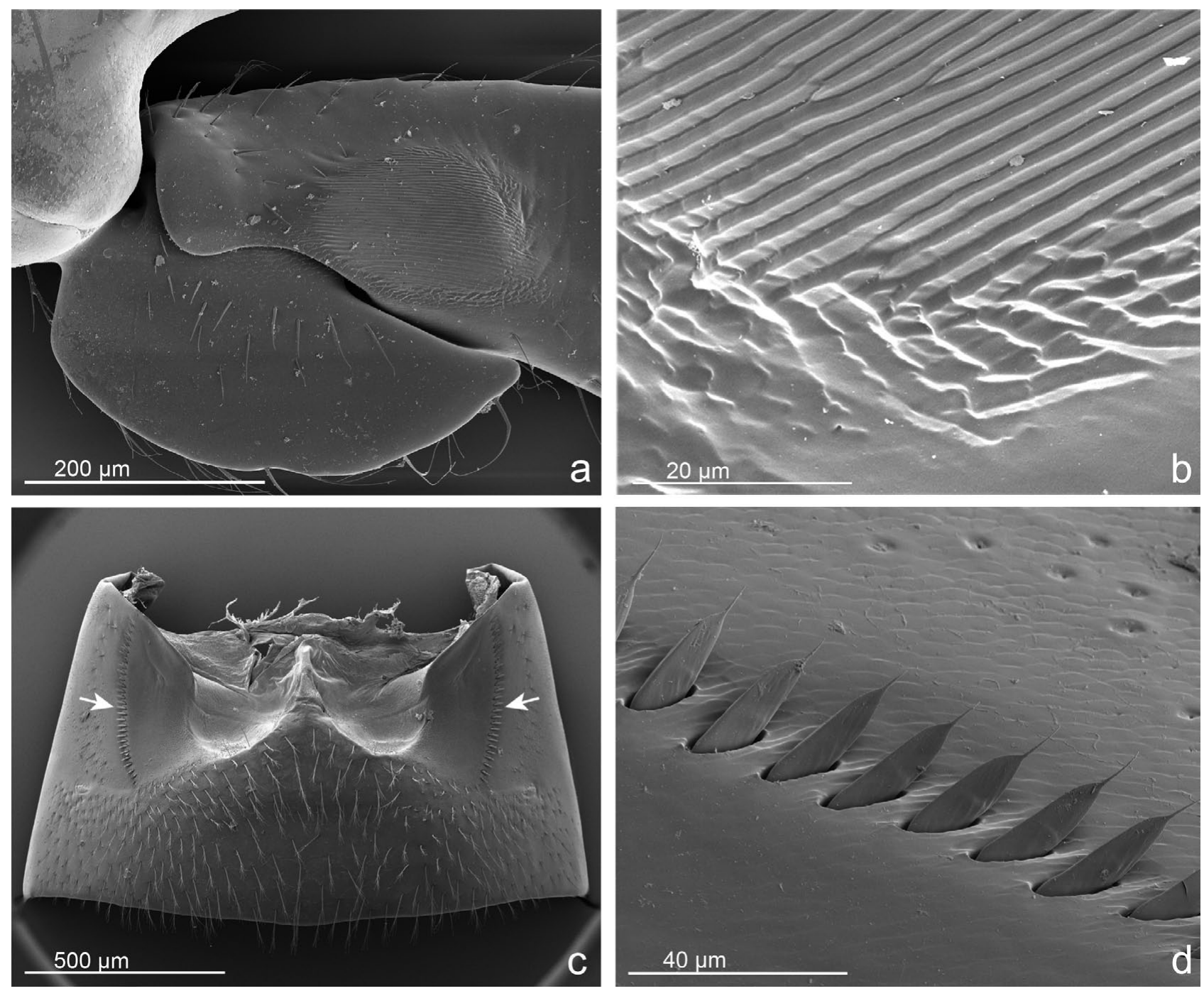

Fig. 2. Paussus favieri female, exemplifying Type I. a - stridulatory file on sub-basal position of left metafemur (posterior side); $b$ close-up of peripheral part of stridulatory file; $\mathrm{c}$ - fused abdominal ventrites 1-3 (fused abdominal sternites II-IV), arrows showing the position of the rows of cuticular spines (scraper); $d$ - close-up of the spines.

Scraper (Fig. 2c-d). The scraper comprises an outwardly curved row (length $415 \mu \mathrm{m}$ ) of cuticular spines (25-30 elements) on abdominal ventrite 2 , posterolateral to hind coxae (Fig. 2c). Each spine (Figs 2d) flattened and subtriangular, $32.56 \pm 3.62 \mu \mathrm{m}$ long, obliquely emerging from an elliptical socket (length $\sim 15 \mu \mathrm{m}$, max width $\sim 6 \mu \mathrm{m}$ ), apically bearing a trichoid projection that is directed upward (Figs 2d; 3). Distance between spines approximately $9.46 \pm 1.50 \mu \mathrm{m}$. The spines are not parallel to one another but radially oriented along the curved row, their apices projecting laterally. Their orientation is parallel to the ridges of the file.

FIB/SEM analysis (Fig. 3a-d). The FIB/SEM dissections reveal that the trigger-like spines of the scraper may not be modified setae, but new complex cuticular structures. Each spine is a cuticular outgrowth of the sternal plate, deeply invaginated in the thickness of the cuticle, not showing a thin cuticular membrane like the typical trichoid sensilla. The spines are solid, rather than hollow, making them strong and the tips are tapered giving them flexibility.
The origin of the trigger-like spines comprising the scraper is unclear, but additional investigation may reveal whether the spines are highly modified setae, or completely novel structures.

Comments. There is a wide range of variation in certain aspects of the Type I stridulatory organ. The scraper varies in the number and shape of the spines, their spacing, and the degree of curvature of the row of spines (e.g., see Escherich, 1898; Nagel, 1987).

Stridulatory organ of the host ant (Fig. $4 \mathrm{a}-\mathrm{f}$ ). The stucture of the stridulatory organ of Pheidole pallidula is very similar to most organs described in ants (see Hölldobler \& Wilson, 1990). It is positioned on the abdominal tergites III-IV (Fig. 4b). The file is located mid-dorsally on the pretergite of the fourth abdominal segment (Fig. 4c-d), while the scraper is located on the posterior margin of the third abdominal tergite (postpetiole) (Fig. 4e-f).

Stridulatory file (Fig. 4c-d). The file is a rounded tegumental area with a very regular organization, characterized by parallel transversally arranged cuticular ridges (Fig. 

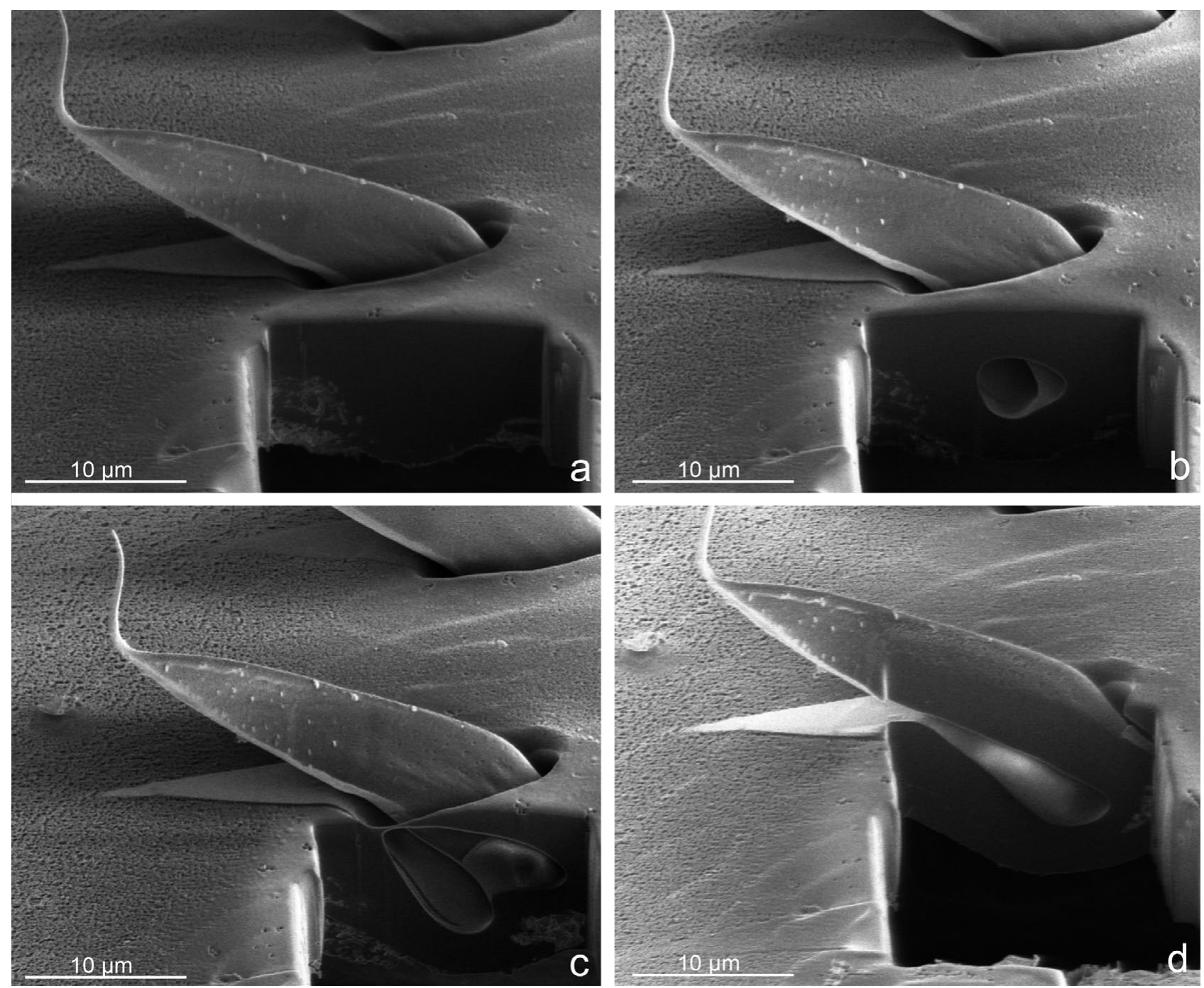

Fig. 3. Cuticular spine of the scraper of Paussus favieri (stridulatory organ Type I), dissected by using FIB/SEM microscope. The micrographs show different stages $(\mathrm{a}-\mathrm{d})$ of the milling process operated by the focused ion beam. Note the thickness of the cuticle at the base of the spine $(a-d)$, the extent of the invaginated part of the spine $(b-d)$, the basal space allowing moderate spine deflection (c-d) and the solid nature of the spine (d). Note that the gold layer, sputtered on the cuticular surface for conductive purposes, was removed by the ions during focusing operations, except under the spines that worked as shelters (triangular whitish "shadows" under the tip of the spines).

4c). This area extends longitudinally for the whole length of the pretergite. The file is easily distinguishable from the surrounding cuticle which is more irregular (Fig. 4d).

Scraper (Fig. 4e-f). The scraper is located on the medial portion of the posterior margin of the third abdominal tergite, bent downward, lying over the file.

\section{Type II ("thorax-femur" type)}

Only known for the genus Euplatyrhopalus (7 species, subtribe Platyrhopalina), this structure was first described by Westwood (1874) but without functional interpretation. Later Fowler (1912) recognized it as a stridulatory organ and hypothesized a function in mating. This organ, present in both sexes, consists of a file composed of a fan of several short ridges, strongly raised and widely separated from one another, located on the internal side of both mesofemora (Figs 1b3; 5a), and a scraper located on each side of metasternum (Fig. 1b2), composed of pointed setiferous protuberances (Fig. 5c-d).

Stridulatory file (Figs $1 \mathrm{~b} 3 ; 5 \mathrm{a}-\mathrm{b}$ ). The Type II file is suboval (maximum length $350 \mu \mathrm{m}$; maximum width 250 $\mu \mathrm{m})$, with maximum width oriented transversally to the leg axis (Fig. 5a); composed of a fan of 9-12 strongly raised ridges (length $214.05 \pm 46.40 \mu \mathrm{m}$ ), longitudinally oriented along leg axis and slightly diverging from base to apex (Fig. $5 \mathrm{a}-\mathrm{b}$ ); ridges about $2-3 \mu \mathrm{m}$ thick and spaced $26.32 \pm 8.87$ $\mu \mathrm{m}$ apart; all ridges complete and not fused to one another.

Scraper (Figs 1b2; 5c-d). The scraper is represented by two curved parallel rows of 5-8 pointed setiferous cuticular knobs, posterolateral to mesocoxae, externally placed on metasternum. Each setiferous protuberance is directed laterally and bears a short seta. (Fig. 5c-d).

Host ant: Unknown. 

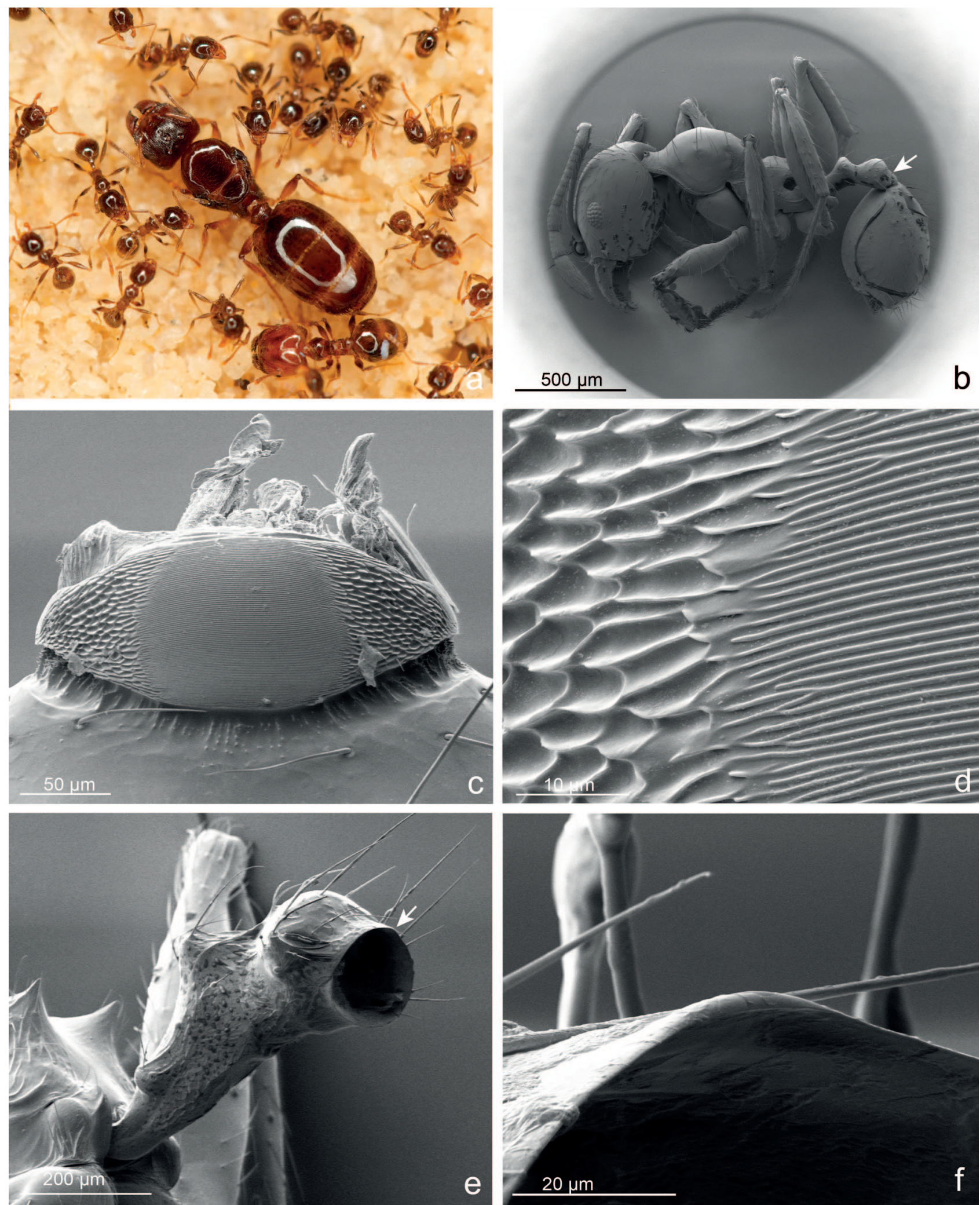

Fig. 4. Pheidole pallidula, exemplifying the Paussus favieri host ant's stridulatory organ. a - part of the colony showing the queen (in the middle), surrounded by workers and one soldier (bottom); b-f, SEM micrographs: b - worker specimen in left lateral view, arrows indicate the position of the stridulatory organ; $\mathrm{c}$ - stridulatory file of soldier specimen on meso-dorsal part of the first gastral segment (i.e., the fourth abdominal segment) showing the elliptical ridged area; $d$ - close-up of left peripheral part of stridulatory file, showing the distinct change of the microsculpture; $\mathrm{e}$ - anterior part of the abdomen of soldier specimen, dissected from the gaster, showing the position of the scraper (arrow) on the posterior edge of the postpetiole (i.e., the third abdominal tergite); $f$ - close-up of the scraper, consisting of a medial cuticular prominence represented by a downward folding of the postpetiole edge. 

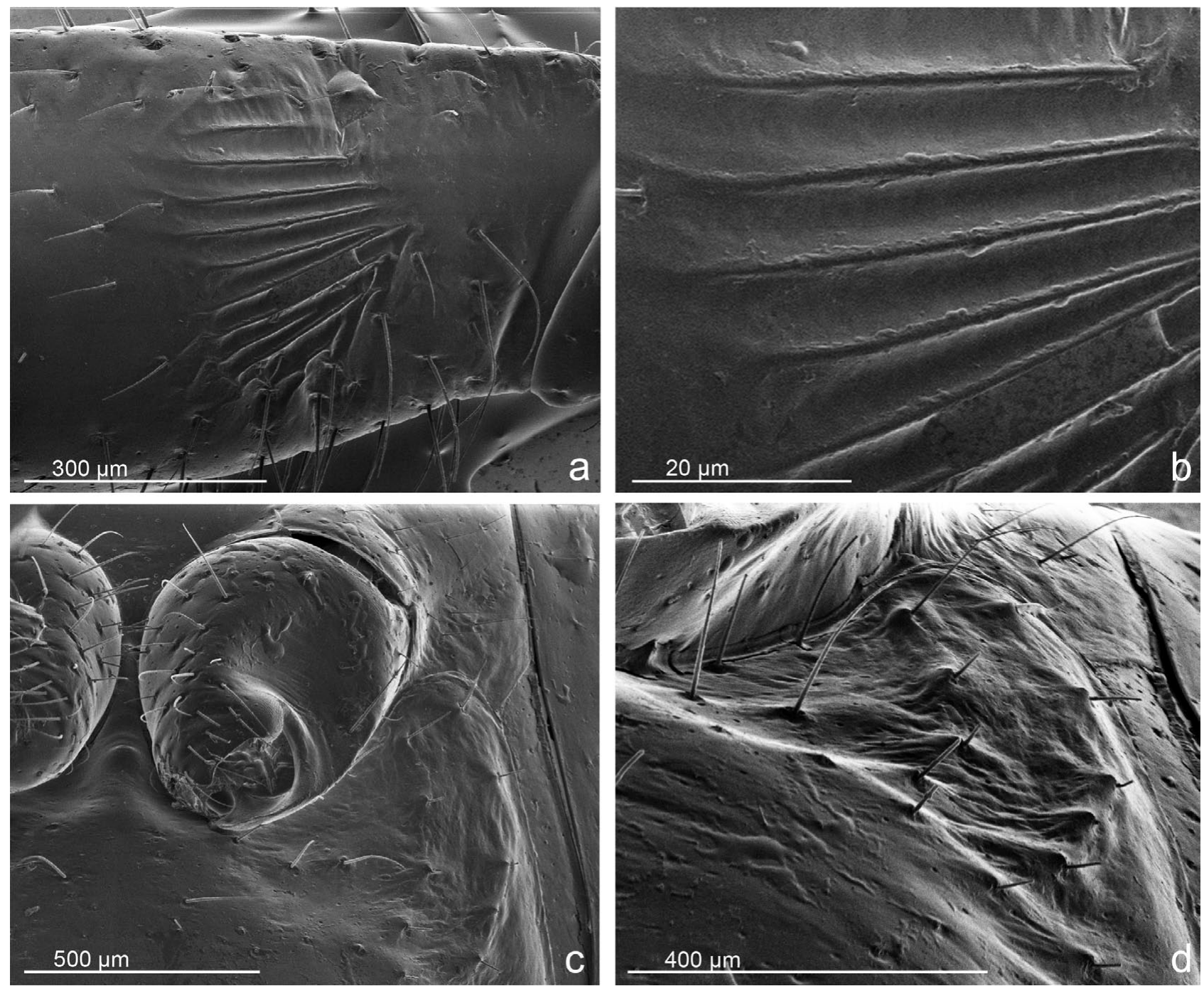

Fig. 5. Euplatyrhopalus vexillifer male, exemplifying Type II. a - stridulatory file in sub-basal position on left mesofemur (posterior side); $\mathrm{b}$ - close-up of medial ridges of stridulatory file; $\mathrm{c}$ - left part of metasternum showing the curved rows of pointed setiferous protuberances (scraper); $\mathrm{d}$ - left part of metasternum in obliquely posterior view showing the length of the cuticular setiferous protuberances of the scraper.

\section{Type III ("femur-thorax" type)}

The Type III stridulatory organ is currently known only in the nominotypical subgenus ( 2 described species) of the small genus Platyrhopalopsis (Luna de Carvalho, 1953); it is absent in P. (Platyrhopalides) badgleyi (see Gahan, 1922). In Type III, the scraper and file are inverted as compared with Types I and II. This organ, present in both sexes, is composed of a wide fan of many fine costae (file), present on each side of metasternum (Figs 1c2; 6a-b), that is rubbed against a scraper positioned basally on the internal side of each mesofemur (Figs 1c3; 6c-d).

Stridulatory file (Figs 1c2; 6a-b). The Type III file comprises a wide cuticular surface (about $1 \mathrm{~mm}^{2}$ ) at anterior corners of metasternum furrowed by a fan of about 100 fine subparallel, elongate ridges (Fig. 6a-b), radially directed; each ridge, $5.25 \pm 1.1 \mu \mathrm{m}$ thick, distant from the adjacent ridge by approximately $5.04 \pm 0.54 \mu \mathrm{m}$; most ridges are complete and parallel, others are incomplete and convergent (Fig. 6b) as in Type I.
Scraper (Figs 1c3; 6c-d). The scraper is composed of a row of 4 small setiferous keels (each about $50 \mu \mathrm{m}$ long, seta excluded), positioned on mesofemur on top of a convex region near the base (Figs 1c3; 6c). Each keel is produced apically and directed longitudinally along the femur axis, thereby redirecting the orientation of the associated seta (Fig. 6d). Setae associated with the keels are well developed and apically branched, like the other femoral setae, but are oriented tangentially to the surface rather than perpendicular to it (Fig. 6c-d). Distances between spines vary between $30-90 \mu \mathrm{m}$.

The host ant of Platyrhopalopsis picteti is unknown, but the host ant of $P$. melleii is Pheidologeton diversus (Myrmicinae) (Luna de Carvalho, 1989; Geiselhardt et al., 2007).

\section{DISCUSSION}

The file and scraper of the three types of stridulatory organs in Paussini are located on different body parts, and therefore they are not homologous, but rather they evolved 

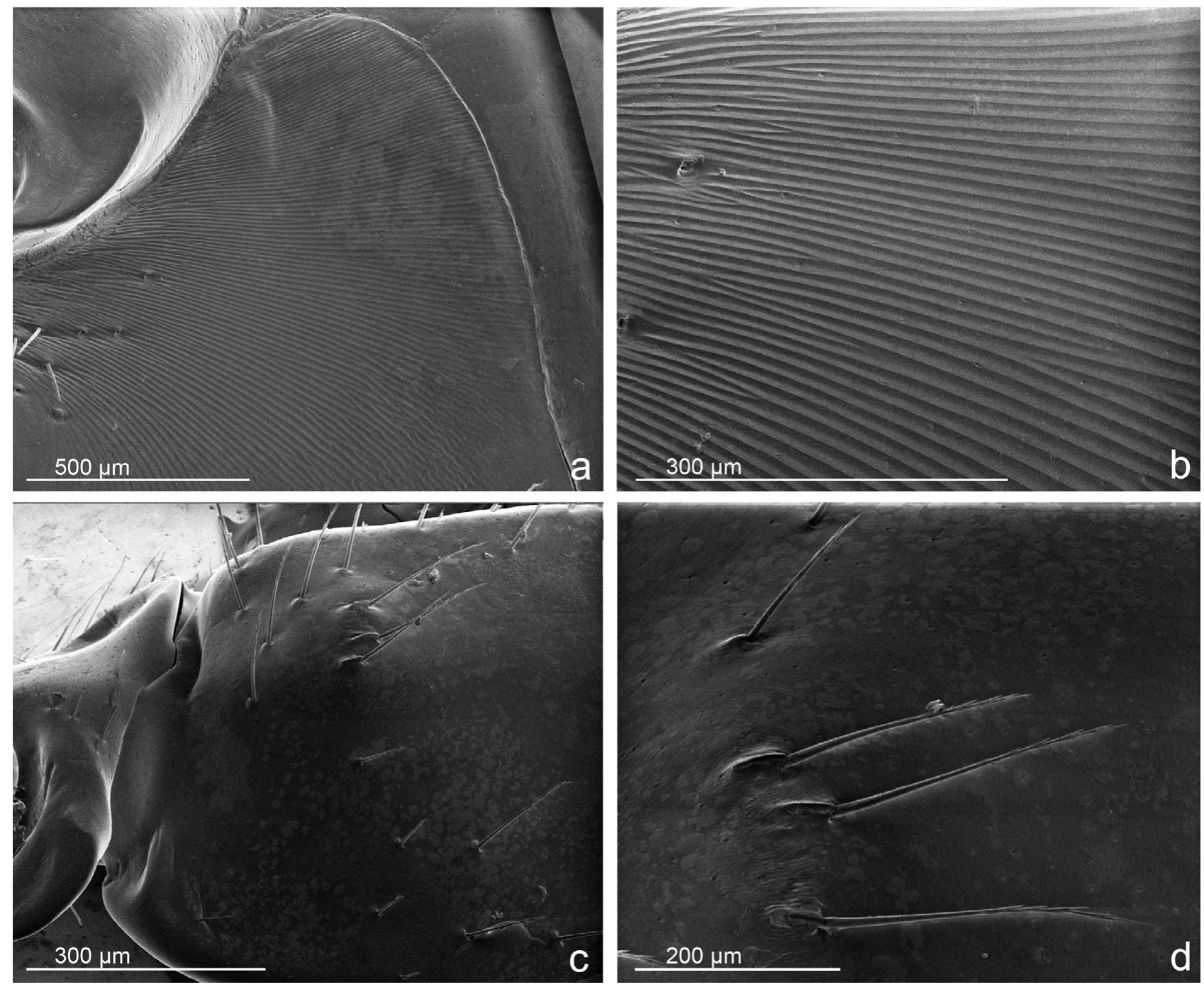

Fig. 6. Platyrhopalopsis picteti male, exemplifying Type III. a - stridulatory file on left part of metasterum showing the length and the fan-like arrangement of the ridges; $b$ - close-up of medial ridges of left stridulatory file; $c$ - strongly convex basal part of left femur showing the arrangement of the pointed setiferous keels (scraper); $d$ - close-up of the setiferous keels of the scraper.

independently, once in Paussina (Type I) (Fig. 1a) and twice in Platyrhopalina (Type II and III) (Fig. 1b-c). That acoustical communication is important to the biology of these beetles is supported by the fact that stridulatory organs evolved three times independently in this group and that each type of organ is present and morphologically similar in all species of these clades (Fig. 7) . The absence of the Type I stridulatory organ in the monotypic Leleupaussus is interesting. However the phylogenetic position of this enigmatic genus is uncertain and we suspect that it lies outside of Paussina, as suggested by Luna de Carvalho (1989). The Type III stridulatory organ occurs only within the subgenus Platyrhopalopsis; it does not occur in the monotypic subgenus Platyrhopalides, containing only Platyrhopalopsis badgleyi. In the absence of a detailed phylogenetic framework for Platyrhopalina, we can only assume that the Type III stridulatory organ evolved in the most recent common ancestor of the nominotypical subgenus rather than the genus.

Paussines can perceive vibratory sound by means of mechanoreceptors. While this may not seem surprising,
Darlington (1950) questioned the ability of paussines to perceive mechanical stimuli since their antennal pedicel is greatly reduced and therefore he suspected that they may lack a Johnston's organ, the widely acknowledged seat of the insect acoustical reception (McIver, 1985; Bailey, 1991; Fedorova \& Zhantiev, 2009). However, a recent study revealed (1) the presence of a well developed, albeit very small, Johnston's organ in P. favieri and (2) that the antennal trichomes serve as mechanoreceptors (in addition to their role facilitating the spread of glandular secretions) and are potentially involved in the reception of vibratory signals (Di Giulio et al., 2012).

Due to the rarity of Paussus, Platyrhopalopsis and Euplatyrhopalus species and the challenges in rearing them, sounds emitted from their stridulatory organs are still poorly known (yet they are actively being investigated in ADG laboratory at Roma Tre), and the biological significance of these sounds remains a matter of speculation (Fowler, 1912; Nagel, 1987; Geiselhardt et al., 2007). Based on the observations of Nagel (1987), stridulation was reported and considered as a response to molestation (Geiselhardt 


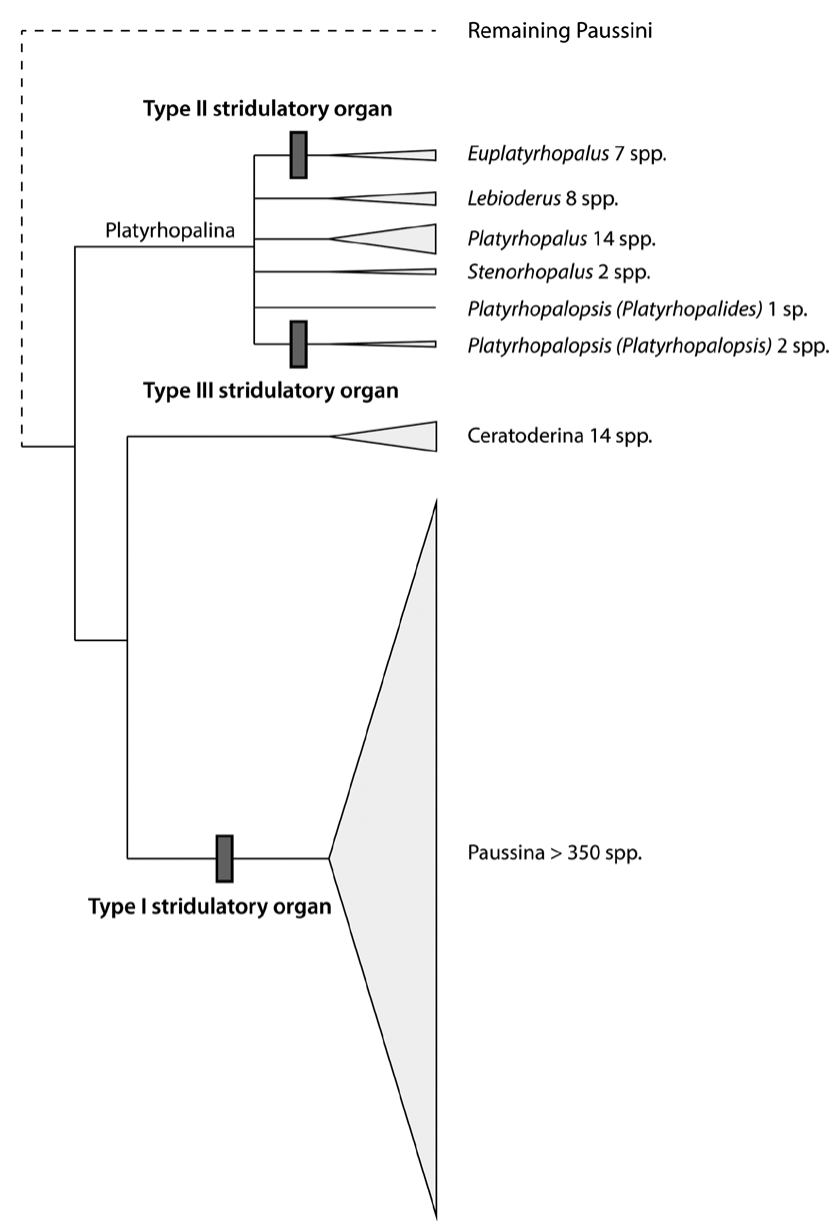

Fig. 7. Summary of phylogenetic relationships of Paussini after Darlington (1950). Terminal clades are drawn proportional to species-richness. The three types of stridulatory organs in Paussini are mapped on the phylogeny (gray hash marks), illustrating the inferred evolutionary independence and significance of each type.

et al. 2007). However, based on the combined indirect evidence described below, we predict that stridulations are involved in both intra and interspecific communication in these myrmecophilous species.

\section{Intraspecific communication}

In many insect species stridulatory organs are well known to function in intraspecific communication. Most commonly males stridulate to attract females and in these species the males have stridulatory organs and the females generally do not (but see Wessel, 2006 for a few exceptions). Observations of $P$. favieri reared in captivity revealed that stridulations are also performed during the pre-mating behavior, especially by females (Maurizi et al., 2012). Luna de Carvalho (1953) also speculated that the function of these organs could be related to mate recognition inside crowded ant nests where acoustical signals could be more effective than visual or chemical signals.

\section{Interspecific communication}

Generally, when stridulatory organs are present in both sexes of a species, as in the case of paussines, they are assumed to also be involved in interspecific communication (but see Wessel, 2006). For a variety of reasons presented below we suspect that the Type I stridulatory organ, present in all members of the diverse genus Paussus, facilitates acoustical communication between these beetles and their ant hosts, similar to the situation demonstrated in larvae and pupae of myrmecophilous butterflies (see De Vries et al., 1993; Barbero et al., 2009a, b; Casacci et al., 2013).

\section{Stridulatory organ of Type I - a key innovation}

The acquisition of a key innovation often precedes an adaptive radiation (Yoder et al., 2010). One of the most apparent key innovations in Paussus is the acquisition of the Type I stridulatory organs (Fig. 7). We suspect that the sophisticated stucture of the scraper (Figs 2d; 3a-d) led to more effective acoustical communication between these beetles and their hosts resulting in an increase in the rate of species diversification in the large genus Paussus (390 species) (Moore \& Robertson, in prep.) (see Fig 7). Unlike the scraper found in Type II (Fig. 5c-d) and Type III (Fig. $6 c-d$ ), the scraper portion of Type I may represent a completely new cuticular structure, rather than modifications and fortifications of setae. The apical projections of the Type I scraper may be the first part of this stucture to come into contact with the fine ridges of the stridulatory file and we predict they are mainly responsible for the fine scraping; however it is also possible that the whole distal edge of the spines can be rubbed aganist the file; such that eventually both parts, the trichoid apex and the distal edge, could be used to create different patterns of vibrations.

Most Paussus species, all of which have the Type I stridulatory organ, have been found in association with Myrmicinae (Geiselhardt et al., 2007), especially Pheidole, whose members are able to stridulate (Moore, 2006). In both ants (Fig. 4a-f) and paussines (Fig. 2a-d), the stridulatory organs are composed of a finely ridged suboval file and some distinct prominences that function as the scraper.

But our most compelling evidence comes from direct observations of the interactions between Paussus favieri and its host ant, Pheidole pallidula, reared in captivity (Maurizi et al., 2012). Males and females of Paussus favieri frequently stridulate (exemplified by the rhythmic movement of the beetle hind legs singly or in tandem) during their interactions with the host ants. Movements of the beetle's hind legs, presumably associated with stridulations, elicited benevolent responses from their host ants in which the minor and major worker ants antennated and actively licked the beetle.

While our knowledge of paussine host ant association is still very limited, there are interesting exceptions to this general pattern in both directions. There are myrmecophilous paussines without stridulatory organs that are known to live with stridulating host ants and some paussine species with stridulatory organs are known to live with non-stridulating ants. Acoustic and chemical communication strategies most certainly vary within this diverse group. Future research aimed at furthering our knowledge of paussine-host associations as well as behavioral studies on the interactions between paussines and their hosts will certainly reveal new insight into the range and relative 
importance of these communication channels within this group.

ACKNOWLEDGEMENTS. We would like to acknowledge P. Nagel (University of Basel, Switzerland) for his help and suggestions that stimulated and improved this paper as well as two anonymous reviewers who provided helpful comments and suggestions on an early version of our manuscript. We are grateful to T. Deuve (Museum National d'Histoire Naturelle, Paris, France) for the loan of Platyrhopaopsis and Euplatyrhopalus studied in the present work. We also thank M. Muzzi for taking the picture of living ants (Fig. 4a). The electron and ion-beam microscopy analyses were performed at LIME (Interdepartimental Lab of Electron Microscopy, University "Roma Tre", Rome, Italy), and funded by the Department of Science of the same University. This research was partially funded by the SYNTHESYS (Synthesis of Systematic Resources, the European Union-funded Integrated Activities grant) Project FR-TAF-1630 to ADG and a National Science Foundation grant (DEB-1256976) to WM and JAR.

\section{REFERENCES}

Arrow G.J. 1904: Sound-production in the lamellicorn beetles. — Trans. Entomol. Soc. Lond. 4: 709-749.

Arrow G.J. 1942: The origin of stridulation in beetles. - Proc. R. Entomol. Soc. Lond. 17: 83-86.

BaILEY W.J. 1991: Acoustic Behaviour of Insects: An Evolutionary Perspective. Chapman \& Hall, London, $225 \mathrm{pp}$.

Barbero F., Thomas J.A., Bonelli S., Balletto E. \& Schönrogge K. 2009a: Queen ants make distinctive sounds that are mimicked by a butterfly social parasite. - Science 373: 782-785.

Barbero F., Thomas J.A., Bonelli S., Balletto E. \& Schönrogge K. 2009b: Acoustical mimicry in a predatory social parasite of ants. - J. Exp. Biol. 212: 4084-4090.

Baroni-Urbani C., Buser M.W. \& Schilliger E. 1988: Substrate vibration during recruitment in ant social organization. - Insectes Soc. 35: 241-250.

BAUER T. 1976: Experiments concerning biological value of stridulation in Coleoptera. - J. Comp. Ethol. 42: 57-65

Casacci L.P., Thomas J.A., Sala M., Treanor D., Bonelli S., Balletto E. \& SchÖNROGGe K. 2013: Ant pupae employ acoustics to communicate social status in their colony's hierarchy. - Curr. Biol. 23: 323-327.

Claridge M.F. 1974: Stridulation and defensive behavior in the ground beetle, Cychrus caraboides (L.). - J. Entomol. (A) 49: $7-15$.

Darlington P.J. 1950: Paussid beetles. - Trans. Am. Entomol. Soc. 76: 47-142.

De VRIES P.J. 1990: Enhancement of symbioses between butterfly caterpillars and ants by vibrational communication. - Science 248: 1104-1106.

De VRIES P.J. 1991a: Call production by myrmecophilous riodinid and lycaenid butterfly caterpillars (Lepidoptera): morphological, acoustical, functional, and evolutionary patterns. - Am. Mus. Novit. 3025: 23.

DE VRIES P.J. 1991b: Detecting and recording the calls produced by butterfly caterpillars and ants. - J. Res. Lepid. 28: 258-262.

De Vries P.J., Cocroft R.B. \& Thomas J.A. 1993: Comparison of acoustical signals in Maculinea butterfly caterpillars and their obligate host Myrmica ants. - Biol. J. Linn. Soc. 49: 229-238.

Di Giulio A., Rossi Stacconi M.V. \& Romani R. 2009: Fine structure of the antennal glands of the ant nest beetle Paussus favieri (Coleoptera, Carabidae, Paussini). - Arthr. Struct. Dev. 38: $293-302$.
Di Giulio A., Maurizi E., Hlaváč P. \& Moore W. 2011: The longawaited first instar larva of Paussus favieri (Coleoptera: Carabidae: Paussini). — Eur. J. Entomol. 108: 127-138.

Di Giulio A., Maurizi E., Rossi Stacconi M.V. \& Romani R. 2012: Functional structure of antennal sensilla in the myrmecophilous beetle Paussus favieri (Coleoptera, Carabidae, Paussini). - Micron 43: 705-719.

DUMORTIER B. 1963: Ethological and physiological study of sound emissions in Arthropoda. In Busnel R.G. (ed.): Acoustic Behavior of Animals. Elsevier, Amsterdam, pp. 583-654.

EsCHERICH K. 1898: Zur Anatomie und Biologie von Paussus turcicus Friv. - Zoologische Jahrbücher (Abt. Syst. Geogr. Biol. Thiere) 12: 27-70.

EsCHeRICH K. 1899: Zur naturgeschichte von Paussus favieri Fairm. - Verh. Zool. Bot. Ges. Wien 49: 278-283.

Fedorova M.V. \& Zhantiev R.D. 2009: Structure and function of the Johnston's organ in Fleuria lacustris Kieff. males (Diptera, Chironomidae). - Entomol. Rev. 89: 896-902.

Ferreira R.S., Poteaux C., Delabie J.H.C., Fresneau D. \& RyBAK F. 2010: Stridulations reveal cryptic speciation in Neotropical sympatric ants. - PLOS ONE 5(12): e15363.

ForRest T.G., ReAd M.P., FARRIS H.E. \& Hoy R.R. 1997: A tympanal hearing organ in scarab beetles. - J. Exp. Biol. 200: 601-606.

FowLER W.W. 1912: Coleoptera. General introduction and Cicindelidae to Paussidae. In Shipley A.E. (ed.): The Fauna of British India, Including Ceylon and Burma. Taylor and Francis, London, $\mathrm{xx}+529 \mathrm{pp}$.

GaHAN C.J. 1900: Stridulation organs in Coleoptera. - Trans. Entomol. Soc. Lond. 48: 433-452.

GaHAN C.J. 1922: Remarks on stridulatory organs. - Proc. Entomol. Soc. Lond. 1921: iv-v.

Geiselhardt S.F., Geiselhardt S. \& PeschKe K. 2006: Chemical mimicry of cuticular hydrocarbons - how does Eremostibes opacus gain access to breeding burrows of its host Parastizopus armaticeps (Coleoptera, Tenebrionidae)? - Chemoecology 16: 59-68.

Geiselhardt S.F., Peschke K. \& Nagel P. 2007: A review of myrmecophily in ant nest beetles (Coleoptera: Carabidae: Paussinae): linking early observations with recent findings. - Naturwissenschaften 94: 871-894.

Hickling R. \& Brown R.L. 2000: Analysis of acoustic communication by ants. - J. Acoust. Soc. Am. 108: 1920-1929.

HölLdOBLER B. 1999: Multimodal signals in ant communication. - J. Comp. Physiol. 184: 129-141.

Hölldobler B. \& Wilson E.O. 1990: The Ants. Springer, Berlin, $732 \mathrm{pp}$.

LANe C. \& Rothschild M. 1965: A case of Müllerian mimicry of sound. - Proc. R. Entomol. Soc. Lond. (A) 40: 156-158.

Le Masne G. 1961a: Observations sur le comportement de Paussus favieri Fairm., hôte de la fourmi Pheidole pallidula Nyl. - Ann. Fac. Sci. Marseille 31: 111-130.

Le MASne G. 1961b: Recherches sur la biologie des animaux myrmecophiles I: L'adoption des Paussus favieri Fairm., par une nouvelle société de Pheidole pallidula Nyl. - C. R. Hebd. Séances Acad. Sci. 253: 1621-1623.

LEHR W. 1914: Die Sinnesorgane der beiden Flügelpaare von $D y$ tiscus marginalis. - Z. Wiss. Zool. 110: 87-150.

LEWIS E.E. \& CANE J.H. 1990: Stridulation as a primary ant-predator defence of a beetle. - Anim. Behav. 40: 1003-1004.

Luna de Carvalho E. 1949: Estudos sobre a familia Paussidae Latreille (Col. Carab. Isochaeta). - Mem. Estud. Mus. Zool. Univ. Coimbra 193: 1-9.

Luna de Carvalho E. 1953: Estudos sobre coleópteros da família Paussidae Latreille. Garcia de Orta 1: 23-41. 
Luna de Carvalho E. 1989: Essai monographique des Coléoptères Protopaussines et Paussines. - Mem. Inst. Invest. Cient. Trop. 70: 1-1028.

McIver S.B. 1985: Mechanoreception. In Kerkut G.A. \& Gilbert L.I. (eds): Comparative Insect Physiology, Biochemistry and Pharmacology. Vol. 6. Pergamon Press, Oxford, UK, pp. 71-132.

MarkL H. 1965: Stridulations in leaf-cutting ants. - Science 149: 1392-1393.

Markl H. \& HöLldobler B. 1978: Recruitment and food-retrieving behavior in Novomessor (Formicidae, Hymenoptera). Vibration signals. - Behav. Ecol. Sociobiol. 4: 183-216.

Masters W.M. 1979: Insect disturbance stridulation: Its defensive role. - Behav. Ecol. Sociobiol. 5: 187-200.

MASTERS W.M. 1980: Insect disturbance stridulation: Characterization of airbone and vibrational components of the sound. J. Comp. Physiol. 135: 259-268.

Maurizi E., Fattorini S., Moore W. \& Di Giulio A. 2012: Behavior of Paussus favieri (Coleoptera, Carabidae, Paussini): a myrmecophilous beetle associated with Pheidole pallidula (Hymenoptera, Formicidae). - Psyche 2012, Article ID 940315, 9 pages; doi:10.1155/2012/940315.

Moore W. 2006: Molecular Phylogenetics, Systematics, and Natural History of the Flanged Bombardier Beetles (Coleoptera: Adephaga: Carabidae: Paussinae). PhD. thesis, The University of Arizona, $293 \mathrm{pp}$.

Mynhardt G. 2013: Declassifying myrmecophily in the Coleoptera to promote the study of ant-beetle symbioses. - Psyche 2013, Article ID 696401, 8 pages; doi:10.1155/2013/696401.

NAGEL P. 1979: Aspects of the evolution of myrmecophilous adaptations in Paussinae (Coleoptera: Carabidae). - Misc. Pap. Agric. Univ. Wageningen 18: 15-34.

NAGEL P. 1987: Arealsystemanalyse afrikanischer Fühlerkäfer (Coleoptera, Carabidae, Paussinae). F. Steiner, Stuttgart, 233 pp.

Nichols S.W. (compiler) \& Schuн R.T. (editor) 1989: The TorreBueno Glossary of Entomology. Revised Edition of A Glossary of Entomology by J.R. de la Torre Bueno Including Supplement A by George S. Tulloch. The New York Entomological Society and American Museum of Natural History, New York, xviii +840 pp.
NIEMITS C. 1972: Biochemische, verhaltensphysiologische und morphologische Untersuchungen an Necrophorus vespillo. Forma et Functio 5: 209-230.

Riede K. \& Stueben P.E. 2000: The musical Acalles. Observations on the stridulations of Cryptorhynchinae of the Canaries (Col.: Curculionoidea). Cryptorhynchinae study 13. Snudebiller Studies on Taxonomy, Biology and Ecology of Curculionoidea (CURCULIO-Institut, Mönchengladbach) 1: 307-317.

SCHIÖDTE J.C. 1874: Note sur les organes de stridulation chez les larves des Coléoptères Lamellicornes. - Ann. Soc. Entomol. Fr. (5me sér.) 4: 39.

Schmitt M. \& Traue D. 1990: Bioacoustic and morphological aspects of stridulation in Criocerinae (Coleoptera, Chrysomelidae). - Zool. Anz. 225: 225-240.

SCHNEIDER W. 1950: Über den Erschütterungssinn von Käfern und Fliegen. - Z. Vergl. Physiol. 32: 287-302.

SCHUSTER J. 1983: Acoustical signals of passalid beetles: complex repertoires. Fla Entomol. 66: 486-496.

Spangler H.G. 1988: Hearing in tiger beetles (Cicindelidae). Physiol. Entomol. 13: 447-452.

Temвrock G. 1960: Stridulation und Tagesperiodik bei Cerambyx cerdo L. - Zool. Beitr. (N. F.) 5: 419-441.

Wessel A. 2006: Stridulation in the Coleoptera - an overview. In Drosopoulos S. \& Claridge M.F. (eds): Insect Sounds and Communication: Physiology, Behaviour, Ecology and Evolution. CRC Press, Taylor \& Francis Group, Boca Raton, London, New York, pp. 397-404.

Westwood J.O. 1874: Order - Coleoptera. Section - Pentamera. Family - Paussidae. In Westwood J.O. (ed.): Thesaurus Entomologicus Oxoniensis. Oxford University Press, Oxford, pp. 72-96.

YAGER D.D. 1999: Structure, development, and evolution of insect auditory systems. - Microsc. Res. Tech. 47: 380-400.

YAGER D.D. \& SPANGLER H.G. 1995: Characterization of auditory afferents in the tiger beetle, Cicindela marutha Dow. - J. Comp. Physiol. (A) 176: 587-600.

Yoder J.B., Clancey E., Des Roches S., Eastman J.M., Gentry L., Godsoe W., Hagey T.J., Jochimsen D., Oswald B.P., Robertson J., Sarver B.A.J., Schenk J.J., Spear S.F. \& Harmon L.J. 2010: Ecological opportunity and the origin of adaptive radiations. - J. Evol. Biol. 23: 1581-1596.

Received February 4, 2014; revised and accepted May 26, 2014 Prepublished online September 12, 2014 